\title{
A Criatividade em Cidades Por Meio do Design Estratégico
}

\author{
The Creativity on Cities Through the Strategic Design
}

STOFFEL, Hiparcio R.; Doutorando em Design na Universidade UNISINOS e Mestre em Indústria Criativa pela Universidade FEEVALE

hiparcio@gmail.com

\section{Resumo}

Este artigo analisa como o Design Estratégico (MANZINI, 2008) pode contribuir com a criatividade e inovação social espaços urbanos, especialmente nas cidades criativas (LANDRY; BIANCHINI 1995). Assumimos como premissas que o design estratégico é um processo projetual (ZURLO, 1999) para a inovação social e as cidades, em particular as criativas, como espaços de estímulo a criatividade, a atividade empreendedora e a inovação (LANDRY, 1996). O trabalho é estruturado em três partes, a primeira analisa as cidades criativas, buscando identificar os principais fatores que tornam uma cidade criativa e como desenvolvê-la. A segunda parte analisa o design estratégico, cercando o seu papel na inovação social e como uma cidade pode promove-la. A última parte, a conclusão, apresenta as interações das ideias analisadas e como o design estratégico colabora com o desenvolvimento das cidades criativas.

Palavras Chave: Design Estratégico, Cidades Criativas, Sustentabilidade e Inovação Social.

\begin{abstract}
This article analyzes how the Strategic Design (MANZINI, 2008) can contribute to social creativity and urban spaces, especially in creative cities (LANDRY, 1996). We assume as premises that strategic design is a design process (ZURLO, 1999) for social innovation and cities, in particular creative ones, as spaces to stimulate creativity, entrepreneurship and innovation (LANDRY; BIANCHINI 1995). The work is structured in three parts, the first analyzes the creative cities, seeking to identify the main factors that make a city creative and how to develop it. The second part looks at strategic design, surrounding its role in social innovation and how a city can promote it. The last part, the conclusion, presents the interactions of the ideas analyzed and how the strategic design collaborates with the development of the creative cities.
\end{abstract}

Keywords: Strategic Design, Creative Cities, Sustainability and Social Innovation. 


\section{As cidades no contexto urbano e a necessidade de uma cidade mais criativas}

O crescente aumento na concentração da população em perímetros urbanos, ou seja, nas cidades tem elevado a necessidade e a complexidade de soluções para atender as demandas da sociedade, especialmente no contexto urbano. Segundo as Nações Unidas, atualmente há 7 bilhões de pessoas no globo, com previsão de se alcançar a marca de 11 bilhões até 2100, concentrando $54 \%$ em espaços urbanos, com previsão que chegue aos $80 \%$ até 2020 . Este cenário chama as cidades a um desafio de encontrar soluções, muitas vezes imprecisos, que envolvem muitas partes interessadas e com necessidades muitas vezes conflitantes (RITTEL; WEBBER, 1973; BUCHANAN;1992).

Como consequência, o número de megacidades, as cidades com mais de 10 milhões de habitantes, é também crescente. Estima-se que devamos chegar a 29 megacidades até 2025, em comparação as 16 existentes em 2009, incluindo as cidades de São Paulo e Rio de Janeiro (EUISSESPAS, 2012).

Segundo o relatório de megatendências do Instituto de Estudos de Segurança da União Europeia (EUISS-ESPAS, 2012), países desenvolvidos e países emergentes continuarão a ser ainda mais urbanizados, com perspectivas de que em 2030, mais de $80 \%$ da população urbana mundial vivá na Ásia, África e América Latina.

Neste contexto, as cidades atuam como uma organização dinâmica, viva e de certa forma complexa. Seus atores, governo, instituições, cidadãos, empresas e academia representam interesses nem sempre convergentes, por vezes contraditórios e paradoxais.

Toda organização, e portanto toda cidade, é de certo modo criativa e inovadora. Há uma herança cultural, vocações, ambições e desejos de um futuro melhor (TAKEUCHI e NONAKA, 1995, 2008); VIVANT, 2012). Certo é também dizer que nem todas as cidades são criativas e inovadoras em mesmo grau e compreensão (REIS, 2012).

Como operar um senso de compreensão sobre as capacidades de criativas e de aprendizagem em arranjos de empreendedores em cidades é um desafio de grande potencial, instigante e pouco explorado.

Os conceitos sistematizados de cidade criativa e os que decorrem daí, como indústria criativa (DCMS, 1998) e economia criativa, veem sendo cunhados especialmente a partir da segunda metade da década de 90 e tem como principal referência Charles Landry.

Assim como os próprios conceitos de economia, cidade e indústria criativas (DCMS 1998) estão sendo cunhados na medida em que são experimentados e aplicados (REIS, 2012), igual parece ser a realidade dos referenciais de design estratégico (MANZINI, 2008) e da sistematização da criação de conhecimento nas organizações e, porque não, nas cidades.

As cidades ou comunidades criativas são locais de experimentação e inovação (BRADFORD, 2004), apresentando-se em constante transformação (REIS, 2012), que utilizam a criatividade como forma de explorar os recursos existentes e onde há espaço para a serendipidade (VIVANT, 2012), biassociação ${ }^{1}$ (KOESTLER, 1964) e a intercriatividade ${ }^{2}$ (BRUNS, 2008), expressando o papel

\footnotetext{
${ }^{1}$ bisociation: termo cunhado por Arthur Koestler para distinguir as habilidades de pensar no "plano linear do ato criativo, que opera em mais de um plano", apresentado em The Act of Creation, 1964, p. 36.
} 
do acaso na descoberta e na geração espontânea de ideias, onde a classe criativa encontra tolerância e ambiente para usar seus talentos (FLORIDA, 2002), nas quais as mudanças são corriqueiras (HOWKINS, 2013) e onde as pessoas se unem para fazer da sua comunidade um lugar melhor para viver, trabalhar e se divertir (BRADFORD, 2004; LANDRY, 2008).

A transformação da cidade por meio da sua criatividade deve ser entendida como um Transformação, estruturado em três fases: latência, catálise e consolidação, ver Quadro 01 Processo de Transformação da Cidade - (REIS, 2012) e cita três características essenciais de uma cidade criativa:

- Inovações: capacidade de solucionar problemas e antecipar oportunidades das mais diversas ordens;

- Conexões: entre pessoas e seus espaços e identidades; entre a história urbana, o contexto presente e uma estratégia futura; entre áreas da cidade; entre a cidade e o mundo; entre setores e agentes públicos, privados, da academia e da sociedade civil, em um pacto de governança concreta;

- Cultura: pelo que apresenta de intrinsicamente simbólico, pela identidade, pelos valores compartilhados.

As três características essenciais de uma cidade criativa propostas por Reis (2012) traduzem alguns dos aspectos determinantes para a transformação de uma cidade, com atenção à sua capacidade de solucionar problemas, interrelacionamento e sua identidade cultural.

Quadro 1 - Processo de Transformação da Cidade

\begin{tabular}{|c|c|c|c|}
\hline & Latência & Catálise & Consolidação \\
\hline Criatividade & Esparsa & Em polos & Compartilhada \\
\hline $\begin{array}{c}\text { Liderança das iniciativas } \\
\text { criativas }\end{array}$ & Inexistente & Desencadeadora & Sobrepostos \\
\hline $\begin{array}{c}\text { Mapas geográfico, mental e } \\
\text { emocional }\end{array}$ & Desconhecidos & Ampliados & Em rede \\
\hline Conexões & Nas pontas & Entre nodos & Espaço de todos \\
\hline
\end{tabular}

Fonte: Baseado em Reis (2012)

No livro The Creative City - Index, measuring the pulse of the city (2012) os autores Charles Landry e Jonathan Hyams abordam dez áreas de domínio que as cidades ou comunidades criativas devem dominar, a partir dos quais fazem uma leitura objetiva sobre as determinantes de

\footnotetext{
${ }^{2}$ intercreativity: termo cuja origem é atribuída a Tim Berners-Lee, inventor da Word Wide Web, significando um passo além da mera interação, sendo possível pelo uso não hierárquico e pelos meios de muitos-para-muitos, apresentado em blogs, Wikipedia, second life, and beyond, 2008, p. 16 de Axel Bruns.
} 
uma cidade criativa. Uma característica importante de sua obra é a abrangência dos temas abarcados pelos domínios propostos.

Os 10 domínios indicados pelos autores são:

- Política e Estrutura Pública;

- Distinção, diversidade, vitalidade e expressão;

- Abertura, confiança, acessibilidade e participação;

- Empreendedorismo, exploração e inovação;

- Liderança estratégica, agilidade e visão;

- Desenvolvimento de talentos e estrutura de aprendizado;

- Comunicação, conectividade, networking e mídia;

- O lugar e o "place making";

- Qualidade de vida e bem-estar,

- Profissionalismo e efetividade

Em Dimensões e Indicadores da Capacidade Criativa em Cidades, Stoffel (2017) apresenta três dimensões criativas e habilitantes para o fomento e desenvolvimento de comunidades criativas e inovadoras: (1) ambientes criativos; (2) processos criativos e; (3) ativos criativos, desdobrados em categorias, como demonstrado no Quadro 2 - Dimensões e categorias habilitantes.

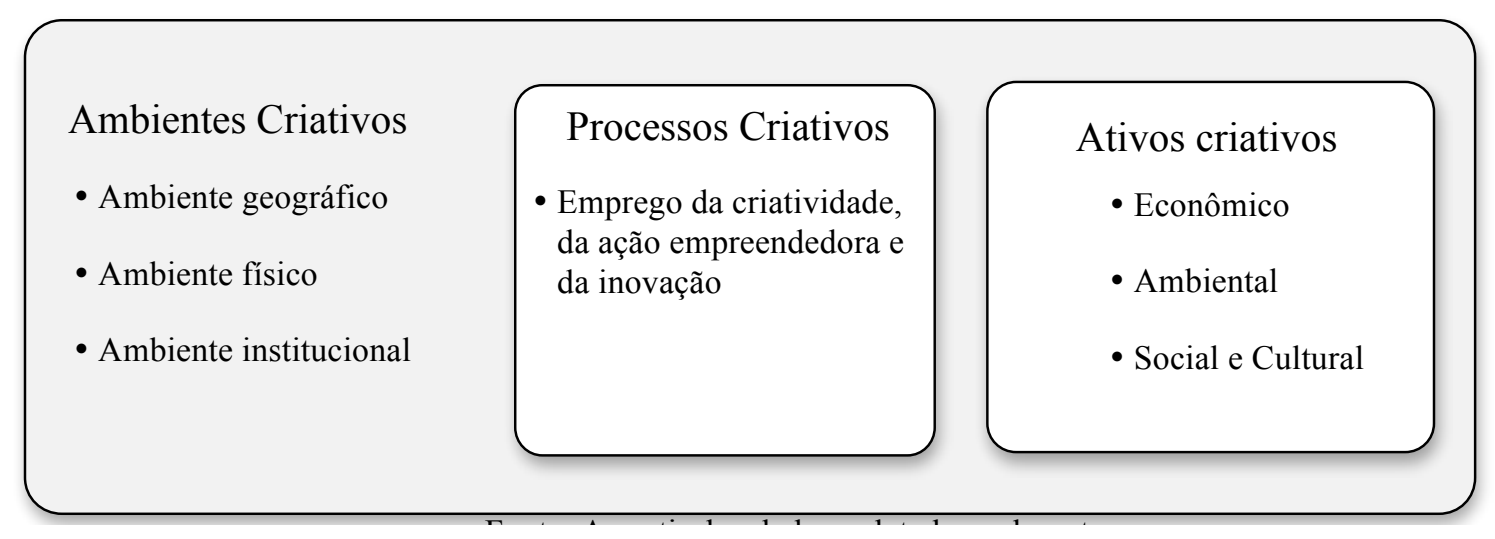

Quadro 2- Dimensões e categorias habilitantes (Stoffel, 2017)

A dimensão ambientes criativos foca as condições facilitadoras e promotoras para a atividade criativa empreendedora e de inovação, estruturada nos ambientes geográfico, contemplando os espaços criativos, áreas reocupadas e gentrificadas, físico, contemplando a infraestrutura disponibilizada para apoio à atividade criativa e envolve segurança, mobilidade, educação empreendedora, conectividade, o consumo do produto cultural e criativo (HOWKINS, 2013) e por fim o ambiente institucional, que aborda promoção e incentivo à iniciativa criativa, empreendedora e de inovação, a uma visão compartilhada de transformação e governança local.

A dimensão processos criativos foca na capacidade de inovação da cidade ou comunidade criativa por meio do emprego da criatividade, da ação empreendedora e da inovação, tendo como fonte o conhecimento. 
A dimensão ativos criativos foca a produção e consumo criativo como efeitos obtidos pela prática dos pilares Ambientes Criativos e Processos Criativos, categorizados em Econômico, Ambiental, Social e Cultural.

Ainda que dificilmente se defina o conceito de cidade criativa de forma absoluta, é razoável entendê-la como uma espaço de experimentação, colaboração e co-criação, que estimule o desenvolvimento da indústria criativa (DCMS, 1998) e que promova as capacidades e condições habilitantes ao emprego da criatividade, da ação empreendedora e da inovação para a produção de bens, serviços e soluções suficientes para criar sentido e oferecer valor às pessoas e à comunidade, tanto econômico, como ambiental, social e cultural.

\section{O Design Estratégico e a Inovação Social}

Ainda que não se possa projetar uma cidade criativa, empreendedora e inovadora, muito há com que podemos contribuir no desenvolvimento das condições e plataformas habilitantes (Manzini, 2008) para o exercício da inovação social, onde o design estratégico representa um potencial papel de relevância na estudo, adoção e aprimoramento do processo projetual de busca de soluções capazes de criar sentido e valor às pessoas.

O design estratégico volta sua atenção ao processo projetual (ZURLO, 1999; apud MANZINI, 1999), contudo sem perder atenção aos efeitos sociais, incluído sustentabilidade, proporcionadas pelas inovações conduzidas pelo pensamento estratégico do design, que de certa forma, se propõe a pensar para além das questões mais operacionais e obvias na soluções de demandas trazidas à análise.

As consequências da crescente concentração urbana têm trazido a tona a necessidade de lidarmos com demandas cada mais complexas, dinâmicas, imprevisíveis e fluídas (BAUMAN, 2000), por vezes com interesses contraditórios ou até conflitantes.

Segundo Leite (2012, p.8), são três aspectos que ampliam a necessidade por novos modelos: "(a) dois terços do consumo mundial de energia advêm das cidades, (b) $75 \%$ dos resíduos são gerados nas cidades e (c) vive-se um processo dramático de esgotamento dos recursos naturais".

O enfrentamento desta característica de demandas e problemas, em geral definidos com pouca precisão ou delimitação, os chamados wicked problems (RITTEL; WEBBER, 1973; BUCHANAN;1992), chamam por uma abordagem cada vez menos descritiva e prescritiva (CROSS, 2000) e mais integradora (JONES, 1970) e caracterizada pelo envolvimento e colaboração de designers, com ou sem formação em design, aludindo o fato de todas as pessoas fazerem design, o chamado co-design (SANDERS, 2001).

Os problemas complexos por vezes demandas um processo que seja capaz de aprender tanto nos esforços de definição do problema, quanto na descoberta das soluções mais adequadas as intenções pretendidas num esforço simultâneo de aproximação nos espaços do problema e da solução, através de um desenvolvimento sistemático de análise evolução contínua (DOSRT, 2006).

Christopher Jones (1970) sugere um processo de design organizado em três etapas, (a)Divergência, orientada a estender as fronteiras do problema inicial e os espaços de busca de compreensão do problema, (b)Transformação, orientada a criatividade, experimentação e 
definição mais clara do problema, e (c)Convergência, orientada a identificação da solução final.

Neste sentido a participação e engajamento das pessoas na operação do processo de design, representa importante característica do design estratégico (MANZINI, 2015), o que corrobora a ascensão da classe criativa, explorando a criatividade difundida ( MANZINI, 2006) e a criatividade coletiva (SANDRES, 20010, também chamados de trabalhadores e talentos criativos (FLORIDA, 2011), já tangenciando os aspectos relativos ao consumo criativo, ilustrando a economia criativa, e algumas características determinantes de cidades criativas, como dinâmicas de inovação mais horizontais e distribuídas (SHEERIN, et al., 2013).

Em Design para a Inovação Social e Sustentabilidade, Manzini (2008) aborda a necessidade e importância da inovação social, em particular sobre seus impactos na sustentabilidade. Destaca que não há como projetizar uma cidade ou comunidade criativa e inovadora de forma preditiva, mas que há muito a contribuir para que os esforços de desenvolvimento de ecossistemas de inovação se formem e sejam desenvolvidos. 0 autor destaca 07 plataformas habilitantes para suportar uma variedade de organizações colaborativas:

- Agências para a inovação social que possam operar como catalisadores de novas iniciativas de inovação social e para sustentabilidade;

- Espaços Flexíveis que possam ser usados por comunidades em um mix de funções públicas e privadas;

- Sistemas de conexão capazes de interligar pessoas/ produtos/ serviços;

- Produtos multiusuário concebidos para uso compartilhado;

- Equipamentos semiprofissionais que possam ser usados por amadores para que tenham acesso a eficiência e qualidade disponível;

- Espaços experimentais como incubadoras de novas empresas sociais;

- Sistemas avançados de produtos e serviços para tornar mais fácil e fluído o funcionamento das organizações

A inovação social, no âmbito do design estratégico, "refere-se a mudanças no modo como indivíduos ou comunidades agem para resolver seus problemas ou criar novas oportunidades (MANZINI, 2008, p.61-62) e conhecimentos, migrando o foco dos interesses do indivíduo para as demandas da comunidade, especialmente quando as intervenções gerarem soluções e respostas sistêmicas e duradouras (MERONI, 2008).

O conhecimento é um processo humano, dinâmico e social, de transformação de crenças pessoais e um bem coletivo (TAKEUCHI, 2013) e sua criação, do conhecimento, como fonte de criatividade e inovação deve ser entendido como um processo dialético que permite sistematizar o conhecimento criado pelos indivíduos, tornando-o explícito a comunidade criativa e a organização (SOUZA, 2004). A criação de conhecimento se dará com a criação e a interação de sentidos coletivos (SOUZA, 2004), sejam adquiridos por novos membros ou criados pelos membros existentes, surgem e são mantidos nas interações entre os membros da organização (COOK e YANOW, 1993).

O conhecimento é criado através da interação humana, é dinâmico em sua natureza, uma vez que se torna obsoleto no instante em que é criado, e é uma agenda social que orienta indivíduos, organizações e comunidades a fazerem o bem, o que é certo e adequado às pessoas e a sociedade (TAKEUCHI, 2013). 
Os processos criativos são dinamizados pela capacidade de criação, uso e gestão do conhecimento e fortalecidos na medida e que o conhecimento tácito dos indivíduos que compõem a comunidade criativa é tornado explicito a organização A transformação do conhecimento tácito em explícito significa encontrar uma forma de expressar o inexpressível (TAKEUCHI; NONAKA, 2008).

A operação do conhecimento no âmbito do processo de design para a inovação social, o design estratégico, se dá em um espaço e ambiente dinâmico, seja físico ou virtual, que permita a interação entre os atores criativos, a troca de experiências e o aprendizado, sejam em novos saberes ou em soluções às demandas e intenções de origem.

Para Takeuchi e Nonaka $(1995,2008)$ estes espaços são, o que denominam, o ba. O ba significa lugar, espaço, campo, sejam físicos ou virtuais e se refere ao contexto de interação de pessoas, que como pano de fundo, acolhe à conversão do conhecimento não sistematizado, o conhecimento tácito de seus atores criativos e empreendedores, em conhecimentos externalizados e combinados (TAKEUCHI; NONAKA, 2008 ; TAKEUCHI, 2013).

Os quatro modelos de conversão do conhecimento - modelo SECI (TAKEUCHI e NONAKA, 2008):

- Socialização: relação Indivíduo/ Indivíduo pra compartilhar e criar conhecimento tácito através de experiência direta

- Externalização: relação Indivíduo/ Grupo para articular o conhecimento tácito através do diálogo e da reflexão para torna-lo explícito e compartilhado

- Combinação: relação Grupo/ Organização para sistematizar e aplicar o conhecimento

- Internalização: relação Organização/Indivíduo para aprender e adquirir o conhecimento tácito na prática a partir do compartilhamento e reflexão do conhecimento explícito

O design estratégico, como um atividade de projetação, é operada a partir de um cultura de design (ZURLO, 1999; apud MANZINI, 1999), caracterizado por um sistema de regras, crenças, valores e ferramentas (MERONI, 2008), em espaço de interação e aprendizado, o ba, (TAKEUCHI; NONAKA, 1995, 2008) com as quais as comunidades criativas operam o processo design para oferecer sentido e valor às pessoas.

\section{Considerações finais}

A concentração urbana é um fenômeno que tende a crescer nos próximos anos (EUSSIS, 2012) o que leva as cidades a lidarem com demandas e problemas potencialmente mais complexos e difusos, para os quais os interesses das diferentes partes envolvidas, por vezes, são conflitantes e pouco balanceados (RITTEL; WEBBER, 1973; BUCHANAN;1992).

As cidades criativas são espaços de estímulo a criatividade, experimentação e a aprendizagem, onde a criação do conhecimento é um elemento essencial para o pensamento criativo no âmbito do design estratégico como um processo projetual para a inovação social. 
Assumindo as cidades criativas como espações de interação, troca de conhecimento e aprendizagem, o ba (TAKEUCHI; NONAKA, 1995, 2008), o papel do designer, com ou sem formação em design (MANZINI, 2015), se mistura com a do trabalhar criativo (FLORIDA, 2011 ) na busca do melhor entendimento do problema e das potenciais soluções (JONES, 1970 ).

O design estratégico como processo projetual para a inovação social e sustentável se propõe a oferecer um olhar estratégico a cerca das demandas, problemas ou não, permitindo estudar o briefing inicial com um alargamento das fronteiras originais dos problemas para que se alcance soluções menos convencionais e básicas (CROSS, 2000 ; JONES, 1970).

Ainda que não se consiga planejar uma cidade ou ecossistema criativos (MANZINI, 2008), muito há com o que colaborar. Neste sentido o design estratégico atua como uma abordagem de processo projetual com intenções de sustentabilidade, centralidade nas pessoas e geração de valor, tanto econômico, quanto ambiental, social e cultural, na tratativa de problemas complexos, buscando a criação de sentido e bem-estar às pessoas e à sociedade.

\section{Referências}

BAUMAN, Z. Liquid Modernity. Cambridge: Polity Press, 2000

BRADFORD, Neil. Creative Cities Structured Policy Dialogue Backgrounder. Ottawa: Canadian Policy Research Networks, 2004. Disponível em www.cprn.org/doc.cfm?doc=1081\&i=en

BRUNS, Axel. Blogs, Wikipedia, Second Live and Beyond: from production to produsage. New York: Peter Lang Publishing, 2008.

BUCHANAN, Richard. Wicked problems in Design Thinking. Design Issues, The MIT Press, v.8, n.2, p.5-21, 1992

CROSS, Nigel. Engineering Design Methods: strategies for product design. Chichester: John Wiley\&Sons, 2000

COOK, S. e YANOW, D. Organizational Learning: a theory of action perspective. Massachusetts: Addison-Wesley, 1978.

DCMS (Department of Culture, Media and Sport, UK Government). Creative Industries Mapping Documents, 1998. Disponível em: https://www.gov.uk/government/publications/creativeindustries-mapping- documents-1998.

DORST, K. Design Problems and Designy Paradoxes. Design Issues, Cambridge, v.22, n.3, p.4-17, 2006

EUISS; ESPAS. Global Trends 2030: citizens in an interconnected world. EUISS, 2012.

FALS BORDA, O; RAHMAN, M.A. Action and Knowlodge: Breaking the monopoly with participatory action-research. New York: The Apex Press 1991.

FLORIDA, Richard. A Ascenção da Classe Criativa. Porto Alegre: L\&PM, 2011 
HOWKINS, John. Economia Criativa. São Paulo: M.Books, 2013

JONES, Christopher. Design Methods: seeds of human futures. New York: John Willey\&Sons, 1970 KOESTLER, Arthur. The Act of Creation. New York: Dell, 1967

LANDRY, Charles e BIANCHINI, Franco. The Creative City. London: Demos, 1995

LANDRY, Charles e Hyams, Jonathan. The Creative City - Index, measuring the pulse of the city, 2012

LEITE, Carlos. Cidades sustentáveis e inteligentes. 1. ed. São Paulo: Bookman, 2012. V.1.

MANZINI, Ezio. Design for Sustainability. How to design sustainable solutions. Milano: 2004. In: Sustainable Everyday Project. Milano: INDACO, Politecnico di Milano, 2006. P. 1-11

MANZINI, Ezio. Design para a Inovação Social e Sustentabilidade: Comunidades criativas, organizações colaborativas e novas redes projetuais. Rio de janeiro: E-papers Serviços Editoriais, 2008

Design, When Everybody Designs. An introduction to design for social innovation. Cambridge: The MIT Press, 2015

MERONI, Anna. Strategic Design: where are we now? Reflection around the foundations of a recente discipline. Strategic Design Research Journal, v.1, n.1, Dec 1, p.31-38. 2008

REIS, Ana Carla Fonseca. Cidades Criativas: da teoria à prática. São Paulo: SESI SP Editora, 2012

RITTEL, H.W. J.; WEBBER, M.M. Dilemmas in a General Theory of Planning. Policy Science 4, p. 155-169, 1973

SANDERS, E.B.N. Collective Creativity. LOOP: AIGA Journal of Interaction Design Education, [S.1.: s.n], n.3, ago. 2001.

SHEERIN, B.; DIVEKAR, S.; ALCOCER, F.; TEIXEIRA C. Design Process as Innovation Technology for Creating Value in Emerging Markets: The Dream:IN Project. In press, 2013.

STOFFEL, Hiparcio R. Dimensões e Indicadores da Capacidade Criativa em Cidades. Dissertação de Mestrado em Indústria Criativa, Feevale, 2017

SOUZA, Yeda S. Organizações de Aprendizagem ou Aprendizagem Organizacional. RAE-eletrônica, v. 3, n.1, Art5, jan/jun, 2004

TAKEUCHI, Hirotaka. Knowledge- Basead View of Strategy. Madrid: Universia Business Review, n. 40, 2013

TAKEUCHI, Hirotaka; NONAKA, Ikujiro. Knowledge Creation Company. New York: Oxford University Press , 1995 


\section{Artigo Completo}

. Gestão do Conhecimento. Porto Alegre 2008

VIVANT, Elsa. O que é uma Cidade Criativa? São Paulo: Editora SENAC, 2012

ZURLO, Francesco. Un modelo di lettura per I Design Strategico. La relazione tra design e strategia nellímpresa contemporenea. Dottorato de Ricera in Disegno Industriale - XI ciclo Politecnico di Milano, 1999. 247 p. 